\title{
Screening Thresholds for the Corneal Tomography in a Myopic Pakistani Population
}

\author{
Sadia Humayun1, Aisha Fawad2, Quratulain Humayun³, Sabahat Arzoo1 and Mazhar Ishaq1
}

\begin{abstract}
Objective: To evaluate key corneal tomography parameters for screening refractive surgery patients in Pakistani population.

Study Design: Cross-sectional, observation study.

Place and Duration of Study: Armed Forces Institute of Ophthalmology AFIO, National University of Medical Sciences, Rawalpindi, Pakistan, from August 2013 to December 2016.

Methodology: Myopic patients were evaluated by two separate observers on Allegro Oculyzerll (Wavelight) for normal ocular examination. A total of 20 tomographic parameters, used for pre-refractive surgical evaluation, were included. Normality of data was evaluated using Kolmogorov-Smirnov test. Results for outliers were displayed as $2.5 \%, 5 \%, 95 \%$ and $97.5 \%$ percentiles.

Results: The sample of 451 patients (895 eyes), comprised of $61 \%(n=277)$ females and $39 \%(n=174)$ males $(39 \%)$. The mean age was $26 \pm 6.4$ years (range of $18-62$ years, $M=F$ ). Normal mean anterior segment values included; flat simulated keratometry (K1) $42.9 \pm 1.44$ diopters (D), steep K2 $43.9 \pm 1.52 \mathrm{D}, \mathrm{K}$ mean $43.4 \pm 1.43 \mathrm{D}, \mathrm{K}$ maximum $44.6 \pm 1.56 \mathrm{D}$, astigmatism $-0.96 \pm 0.97 \mathrm{D}$, anterior chamber depth (ACD) $3.19 \pm 0.28 \mathrm{~mm}$, front elevation at the thinnest point $4.11 \pm 2.44 \mathrm{um}$, and that at the back was $7.56 \pm 4.52$ um progression index $(\mathrm{PI})$ maximum $1.14 \pm 0.17$. Ambrosio relational thickness maximum (ART max) $487.5 \pm 89.0$ and pachymetry at thinnest point $542.2 \pm 31.1 \mathrm{um}$.

Conclusion: The study demonstrates key corneal tomography parameters, which can be useful for screening refractive surgery patients in Pakistani population.
\end{abstract}

Key Words: Refractive surgery, Corneal tomography, Screening, Keratometry.

\section{INTRODUCTION}

The standard method used for screening patients for refractive surgery is corneal tomography, ${ }^{1}$ which has wide range of applications in various other procedures. These include post-refractive intraocular lens (IOL) power computation, 2 preoperative and postoperative evaluation of phakic IOLs, calculating the keratometric index, collagen crosslinking and intra-stromal corneal rings. ${ }^{3}$ It is a valuable tool for evaluating diseases related to changes in corneal shape, especially for the diagnosis of keratoconus, ${ }^{4}$ and monitoring post-surgical corneas. ${ }^{5}$ Precise measurement of anterior segment parameters in normal and keratoconic corneas is extremely important for diagnosing and monitoring corneal related diseases as well as for surgical planning.

1 Department of Refractive Surgery, Armed Forces Institute of Ophthalmology (AFIO), National University of Medical Sciences, Rawalpindi, Pakistan

2 Department of Eye, Combined Military Hospital, Armed Forces Postgraduate Medical Institute, Rawalpindi, Pakistan

3 Department of Epidemiology, Women and Children's Hospital of Buffalo, New York, USA

Correspondence: Dr. Sadia Humayun, Department of Refractive Surgery, Armed Forces Institute of Ophthalmology (AFIO), National University of Medical Sciences, Rawalpindi, Pakistan

E-mail: sadia.humayun@yahoo.com

Received: January 02, 2018; Accepted: September 22, 2018
Efficacy and safety in refractive surgical procedures relies on improving corneal and anterior segment imaging. Three dimensional re-construction of the cornea and anterior segment is provided by digital rotating Scheimpflug tomography. Scheimpflug corneal tomography is effective in detection of changes on front and back surface curvature; and should be considered for screening among refractive candidates. 6 It is anticipated that there would be advances for enhancing the diagnostic and surgical planning capabilities of Scheimplug imaging system. This will improve the safety and efficacy of refractive surgery. Previous studies have shown excellent reproducibility of this device for the automated measurements of anterior segment structures. ${ }^{7}$

For effective screening of patients, cut offs for the normal values and outliers, according to certain geometric population is required. Currently, Pentacam Scheimpflug system (Oculus Optikgerate $\mathrm{GmbH}$ ) uses elevation and pachymetric normative values obtained from varying countries and databases. ${ }^{8}$ Previously, three different sources were used for myopic normative database for corneal elevation, corneal thickness and pachymetric values from North and South American population and Turkey; and these normative values have been used for identifying outliers and screening refractive surgery patients all over the world. 9

It has been established that normative values were different for Turkey from North and South American 
population and that geographic variation is present in tomographic normative values. Similarly, the myopic normative elevation values were found to be different from hyperopic eyes. Furthermore, the United States Food and Drug Administration (FDA) encourage the collection of race-specific data to determine the effectiveness of medical devices. 10 This leads to the need of finding the normative values for myopic corneas, separate from hyperopic eyes in Pakistani geographic area and location, to achieve any clinical significance. This will perhaps help us in better identification of outliers and for better screening of refractive surgery patients in Pakistani population.

The objective of this study was to evaluate key corneal tomography parameters for screening refractive surgery patients in Pakistani population.

\section{METHODOLOGY}

The study was carried out at Armed Forces Institute of Ophthalmology (AFIO), Rawalpindi, from August 2013 to December 2016, after approval from Institutional Review Board and Ethics Committee. It was a cross-sectional study and non-probability/convenience sampling was used for identifying participants for the study. The participants were screened for the eligibility criteria and one or both the eyes were included in the study. Informed consent was obtained from all the individuals who were screened and found eligible for this study. Allegro Oculyzer II (Wavelight) was used for examination of paired eyes of adult patients. The Wavelight Oculyzer II diagnostic device is based on the proven Pentacam HR technology, providing non-contact measurement and analysis of the complete anterior eye segment. Measurements are performed from anterior surface of the cornea to the back of the lens. The integrated, rotating Scheimpflug camera takes up to 50 pictures in real-time with up to 25,000 measuring points. ${ }^{11}$

All incoming individuals were examined by two separate observers for inclusion or exclusion in this study. The disputed cases were exempted from the study. All participants underwent normal ocular examination, which included uncorrected visual acuity (UCVA), corrected distance visual acuity (CDVA), cycloplegic refraction, fundus examination, intraocular pressure, fluorescence tear film break up time (TBUT), and muscle balance. All eyes had a corrected distance visual acuity (CDVA) of $20 / 20$ or better. Only simple and compound myopic patients (range -0.50 to $-12.00 \mathrm{D}$ ) were included in this study. The exclusion criteria were comorbid medical conditions, such as hypertension, diabetes mellitus, glaucoma, keratoconus, and family history of keratoconus. Mixed astigmatism and hyperopic patients were also excluded from the study. The eligible patients were included in the study irrespective of the decision of refractive surgery. This was done to minimize selection bias, if any.
Following is the list of parameters that were included: steep simulated keratometry (K2), flat simulated keratometry (K1), mean $\mathrm{K}$, maximum $\mathrm{K}$ (Kmax), astigmatism magnitude, anterior chamber depth (ACD), front and back elevation at the apex, front and back elevation at the thinnest point, maximum front and back elevation in the central $4.0 \mathrm{~mm}$, average and maximum progression index (PI avg and PI max), average (ART avg), maximum Ambrosio relational thickness (ART max, a measure of the thinnest point divided by maximum progression index), corneal pachymetry at the apex (Pachy apex), thinnest point (Pachy thinnest), difference between apical and thinnest pachymetry measurements, and chamber volume (CV).

Data was entered and analysed into SPSS Version 21. A total of 20 tomographic parameters, clinically important for pre-refractive surgical evaluation, were included in this study. Normality of the data was checked by the Kolmogorov-Smirnov goodness-of-fit test. The normally distributed continuous parameters were expressed as means, \pm standard deviation (SD). Parameters notnormally distributed were expressed as medians interquartile range were IQR. Frequencies with percentages were reported for nominal parameters. Percentiles (5.0, 95.0, 2.5, and 97.5) were computed for each of the parameters to identify outliers.

After calculating screening thresholds for the key corneal tomography parameters, a sub-group analysis was performed to identify differences, in screening thresholds, among males and females. Independent sample t-test (student's t-test) was employed for this purpose. The level of significance was set at $<0.05$.

\section{RESULTS}

A total of 451 patients (895 eyes) were included in the study after thorough screening of eligibility criteria. Out of the selected participants, $61 \%$ were females $(n=277)$ and $39 \%$ were males $(n=174)$.

The mean age of the participants was 26 years (SD 6.4) with a range of 18-62 years and the mean age for male and female groups was found to be similar, i.e. not statistically different from each other $(p=0.387)$. Majority of the sample, around $60 \%$, was under 25 years of age (Table I). Table II shows the percentiles for the parameters included the 5.0 and 95.0 percentiles and the 2.5 and 97.5 percentiles were chosen to identify outliers.

Significant differences among males and females were found for $\mathrm{K} 1, \mathrm{~K} 2$, $\mathrm{K}$ mean, $\mathrm{K}$ max, astigmatism and $\mathrm{ACD}$, front elevation at thinnest point, $\mathrm{PI}$ average and ART average (Table III). No significant differences was observed among the two groups for rest of the parameters, i.e. back elevation at thinnest point, front elevation apex, front elevation max, PI max, ART max, pachy thinnest, pachy apex, and CV. 
Table I: Normal anterior segment values.

\begin{tabular}{|c|c|c|c|c|c|}
\hline Parameters & Mean (SD) & Median (IQR) & Min & Max & $\mathrm{p}$-value (K-S test) \\
\hline K1 (D) & $42.9(1.44)$ & $42.9(2.0)$ & 37.9 & 47.0 & 0.200 \\
\hline K2 (D) & $44.0(1.51)$ & $44.0(2.0)$ & 39.0 & 49.0 & 0.000 \\
\hline K Mean (D) & $43.4(1.43)$ & $43.4(2.0)$ & 37.1 & 47.2 & 0.055 \\
\hline $\mathrm{K} \operatorname{Max}(\mathrm{D})$ & $44.6(1.56)$ & $44.6(2.1)$ & 39.7 & 49.2 & 0.000 \\
\hline Astigmatism (D) & $-0.95(0.97)$ & $-0.90(1.0)$ & -4.7 & 3.7 & 0.000 \\
\hline $\mathrm{ACD}(\mathrm{mm})$ & $3.20(0.28)$ & $3.21(0.34)$ & 1.41 & 4.85 & 0.017 \\
\hline Front Elev at thinnest point $(\mu \mathrm{m})$ & $4.2(2.44)$ & $4.00(2.0)$ & -2 & 31 & 0.000 \\
\hline Back Elev at thinnest point $(\mu \mathrm{m})$ & $7.60(4.52)$ & $7.00(7.0)$ & -3 & 22 & 0.000 \\
\hline Front Elev apex $(\mu \mathrm{m})$ & $3.74(2.02)$ & $4.00(3.0)$ & -1 & 25 & 0.000 \\
\hline Front Elev max $(\mu \mathrm{m})$ & $5.50(2.43)$ & $5.00(3.0)$ & 0 & 18 & 0.000 \\
\hline Back Elev apex $(\mu \mathrm{m})$ & $3.91(4.21)$ & $3.00(6.0)$ & -6 & 20 & 0.000 \\
\hline Back Elev max $(\mu \mathrm{m})$ & $11.9(5.37)$ & $11.0(8.0)$ & -10 & 31 & 0.000 \\
\hline PI max & $1.14(0.17)$ & $1.14(0.24)$ & 0.70 & 1.71 & 0.010 \\
\hline ART max & $487.5(89.0)$ & $477.5(115.4)$ & 291.6 & 839.7 & 0.000 \\
\hline ART avg & $589.9(97.7)$ & $581.1(129.8)$ & 188.3 & 1016 & 0.000 \\
\hline $\mathrm{Pl}$ avg & $0.94(0.12)$ & $0.94(0.16)$ & 0.56 & 1.65 & 0.001 \\
\hline Pachy thinnest $(\mu \mathrm{m})$ & $542.2(31.2)$ & $541.0(40)$ & 429 & 647 & 0.200 \\
\hline Pachy apex $(\mu \mathrm{m})$ & $545.2(30.5)$ & $544.0(40)$ & 434 & 649 & 0.181 \\
\hline Difference & $3.28(1.91)$ & $3.00(2.0)$ & 0 & 13 & 0.000 \\
\hline $\mathrm{CV}$ & $198.1(29.6)$ & $196.0(191)$ & 101 & 292 & 0.000 \\
\hline
\end{tabular}

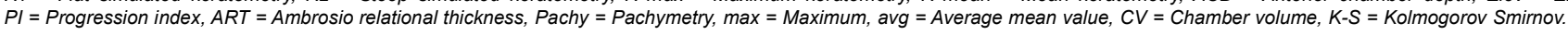

Table II: Values for outlier identification.

\begin{tabular}{l|cccc}
\hline \multirow{2}{*}{ Parameters } & \multicolumn{4}{|c}{ Percentiles } \\
\cline { 2 - 5 } & 5 & 95 & 2.5 & 97.5 \\
\hline K1 $(\mathrm{D})$ & 40.5 & 45.3 & 39.9 & 45.8 \\
\hline K2 $(\mathrm{D})$ & 41.4 & 46.5 & 40.9 & 47.0 \\
\hline KMean $(\mathrm{D})$ & 40.9 & 45.8 & 40.5 & 46.2 \\
\hline K max $(\mathrm{D})$ & 42.0 & 47.3 & 41.4 & 47.6 \\
\hline Astigmatism $(\mathrm{D})$ & -2.6 & 0.6 & -3.0 & 1.06 \\
\hline ACD $(\mathrm{mm})$ & 2.75 & 3.66 & 2.68 & 3.72 \\
\hline Front Elev at thinnest point $(\mu \mathrm{m})$ & 1.00 & 7.00 & 1.0 & 8.0 \\
\hline Back Elev at thinnest point $(\mu \mathrm{m})$ & 1.00 & 16.0 & 0.0 & 17.0 \\
\hline Front Elev apex $(\mu \mathrm{m})$ & 1.00 & 7.00 & 1.0 & 8.0 \\
\hline Front Elev max $(\mu \mathrm{m})$ & 2.00 & 10.0 & 2.0 & 11.0 \\
\hline Back Elev apex $(\mu \mathrm{m})$ & -2.0 & 12.0 & -3.0 & 13.0 \\
\hline Back Elev max $(\mu \mathrm{m})$ & 4.0 & 22.0 & 2.4 & 23.0 \\
\hline Pl max & 0.86 & 1.43 & 0.83 & 1.49 \\
\hline Pl avg & 0.74 & 1.13 & 0.71 & 1.20 \\
\hline ART max & 362.2 & 646.4 & 345.9 & 704.5 \\
\hline ART avg & 454.6 & 758.3 & 435.5 & 800 \\
\hline Pachy thinnest $(\mu \mathrm{m})$ & 492 & 597.2 & 484.4 & 610 \\
\hline Pachy apex $(\mu \mathrm{m})$ & 496.8 & 598.2 & 489 & 613 \\
\hline Difference & 1.00 & 7.00 & 0.0 & 8.0 \\
\hline CV & 151.0 & 250.0 & 142 & 258 \\
\hline K1 $=$ Flat & &
\end{tabular}

$\mathrm{K} 1$ = Flat simulated keratometry, $\mathrm{K} 2$ = Sleep simulated keratometry, $\mathrm{K}$ max $=$ Maximum keratometry, $K$ mean = Mean keratometry, $A C D=$ Anterior chamber depth, Elev = Elevation, $\mathrm{PI}=$ Progression index,$A R T=$ Ambrosio relational thickness, Pachy $=$ Pachymetry, Max $=$ maximum, avg $=$ Average mean value, $\mathrm{CV}=$ Chamber volume, $K-S=$ Kolmogorov Smirnov test .

\section{DISCUSSION}

There has been a rapid change and improvement in preoperative assessment of refractive surgical patients during the past decade. Major role has been played by imaging technique. Corneal tomography is the standard method for screening patients for refractive surgery. 1 Effective screening requires knowledge of normal values and outliers. The Wavelight Oculyzer II and Pentacam,
Table III: Anterior segment values among males and females.

\begin{tabular}{lccc}
\hline Parameters & $\begin{array}{c}\text { Males } \\
\text { Mean }(\mathrm{SD})\end{array}$ & $\begin{array}{c}\text { Females } \\
\text { Mean }(\mathrm{SD})\end{array}$ & $\begin{array}{c}\text { p-value } \\
(<0.05)\end{array}$ \\
\hline K1 $(\mathrm{D})$ & $42.5(1.5)$ & $43.2(1.33)$ & 0.000 \\
\hline K2 $(\mathrm{D})$ & $43.6(1.56)$ & $44.3(1.41)$ & 0.000 \\
\hline K Mean $(\mathrm{D})$ & $43.0(1.53)$ & $43.7(1.31)$ & 0.000 \\
\hline K max $(\mathrm{D})$ & $44.4(1.59)$ & $44.7(1.54)$ & 0.026 \\
\hline Astigmatism $(\mathrm{D})$ & $-0.83(1.12)$ & $-1.03(0.86)$ & 0.004 \\
\hline ACD $(\mathrm{mm})$ & $3.23(0.27)$ & $3.18(0.28)$ & 0.05 \\
\hline Front Elev at thinnest point $(\mu \mathrm{m})$ & $3.98(2.47)$ & $4.34(2.41)$ & 0.029 \\
\hline Back Elev at thinnest point $(\mu \mathrm{m})$ & $7.37(4.92)$ & $7.74(4.25)$ & 0.240 \\
\hline Front Elev apex $(\mu \mathrm{m})$ & $3.64(1.86)$ & $3.81(2.12)$ & 0.232 \\
\hline Front Elev max $(\mu \mathrm{m})$ & $5.40(2.55)$ & $5.56(2.36)$ & 0.358 \\
\hline Back Elev apex $(\mu \mathrm{m})$ & $3.71(4.38)$ & $4.03(4.09)$ & 0.270 \\
\hline Back Elev max $(\mu \mathrm{m})$ & $11.7(5.72)$ & $12.1(5.15)$ & 0.315 \\
\hline PI max & $1.14(0.17)$ & $1.14(0.17)$ & 0.537 \\
\hline PI avg & $0.93(0.13)$ & $.94(0.12)$ & 0.045 \\
\hline ART max & $490(89.7)$ & $485(88.7)$ & 0.496 \\
\hline ART avg & $598(98.1)$ & $584(97.1)$ & 0.036 \\
\hline Pachy thinnest $(\mu \mathrm{m})$ & $542(32.1)$ & $541(30.6)$ & 0.631 \\
\hline Pachy apex $(\mu \mathrm{m})$ & $545(31.1)$ & $544(30.1)$ & 0.671 \\
\hline Difference & $3.3(1.99)$ & $3.27(1.86)$ & 0.846 \\
\hline CV & $199(29.1)$ & $197(29.8)$ & 0.383 \\
\hline
\end{tabular}

Scheimpflug imaging devices provide corneal tomography data (anterior and posterior corneal surface), keratometry, radii of curvature, corneal power (with the axis and amount of astigmatism), pachymetry data (corneal thickness at the apex, at the thinnest corneal point, etc.) corneal eccentricity, anterior chamber depth, pupil diameter, angle size, lens opacification and lens thickness. Several secondary parameters (e.g, progression index, Ambrosio relational thickness) have also been included in newer software, which has further improved sensitivity and specificity in screening refractive surgery patients. ${ }^{12}$ 
The values currently used in the Pentacam system come from different databases including North American, South American, and Turkish populations. Although studies have shown that these values can be applied universally, there are geographical variations. Hence, we ought to investigate our patient population and see if the tomographic values in our patients are different from the published reports.

Gilani et al. reported normative data, based in their population. The keratometry data shows that mean K2 and $\mathrm{K} 1$ values are similar to their results. However, mean front elevation (thinnest), back elevation (thinnest), front elevation (apex), back elevation (apex) were 4.09, 7.56, 3.72 and 3.98 micrometers, respectively, which are slightly higher for our population as compared to the American population in the report by Gilani et al.13 However, the means for front elevation and back elevation (max) were somewhat similar.

Murata et al. analysed the anterior segment of refractive surgery candidates and established the variability pattern in their population regarding corneal volume, anterior chamber volume, and depth and corneal thickness, using the noncontact, three dimensional analyser Pentacam. ${ }^{14}$ They observed that patients with myopia had lesser mean corneal volume and pachymetry, and greater anterior chamber depth and volume compared with hyperopic patients.

Hashemi et al. evaluated the anterior segment measurements according to refractive status in a sample of the Iranian population. ${ }^{15}$ They found that the myopic eyes had steeper corneas than hyperopic eyes; and anterior chamber measurements were significantly higher in the myopic eyes. When compared with our study group, anterior elevation maximum (AEmax) and posterior elevation maximum (PEmax) measurements were slightly higher in Iranian population. However, minimum corneal thickness, $\mathrm{K}$ max, $\mathrm{K}$ mean, $\mathrm{PI}$ avg, $\mathrm{ACD}$, and $\mathrm{CV}$ were similar to our study group in myopic patients.

The importance of geographic specific normative data has been stressed upon in previous reports. Feng et al. looked at normative data from eight different countries and concluded that the current screening guidelines still maintain general applicability. ${ }^{16}$ However, it remains preferable to establish local guidelines, based on data from local population. They noted in their study that local derived thresholds from China, Egypt, and India showed small variations, especially at anterior and posterior elevations at thinnest points. Posterior elevation at thinnest point is slightly higher in China and Egypt populations, when compared with this study group. Similarly, posterior elevation at apex is slightly higher in Indian population, when compared with this study group. After comparing this study results with previously published data, it is recommended the general use of existing screening thresholds for the Pakistani population with special consideration to the differences highlighted in this study.

The Pentacam Scheimpflug imaging devices provide corneal tomography data. Value obtained from Pentacam Scheimflug are applied to North American, South American, and Turkish populations. Tomographic values in the study patients in Pakistan are different from the published reports.

\section{CONCLUSION}

This study provides key parameters, which can be used for screening refractive surgery patients in Pakistan. The calculated tomographic values for male and female patients are slightly different for few parameters in the study population.

\section{REFERENCES}

1. Ambrósio R, Belin MW. Imaging of the cornea: Topography vs tomography. J Refract Surg 2010; 26:847-9.

2. Olsen T, Corydon L, Gimbel H. Intraocular lens power calculation with an improved anterior chamber depth prediction algorithm. J Cataract Refract Surg 1995; 21:313-9

3. Turner SJ, Lee EJ, Hu V, Hollick EJ. Scheimpflug imaging to determine intraocular lens power in vivo. $J$ Cataract Refract Surg 2007; 33:1041-4.

4. De Sanctis U, Loiacono C, Richiardi L, Turco D, Mutani B, Grignolo FM. Sensitivity and specificity of posterior corneal elevation measured by Pentacam in discriminating keratoconus/subclinical keratoconus. Ophthalmology 2008; 115:1534-9

5. Wheeldon CE, Hadden OB, Niederer RL, McGhee CN. Presumed late diffuse lamellar keratitis progressing to interface fluid syndrome. J Cataract Refract Surg 2008; 34: 322-6.

6. Ambrósio R, Valbon BF, Faria-Correia F, Ramos I, Luz A. Scheimpflug imaging for laser refractive surgery. Curr Opin Ophthalmol 2013; 24:310-20.

7. Chen D, Lam AK. Reliability and repeatability of the Pentacam on corneal curvatures. Clin Exp Optom 2009; 92:110-8.

8. Feng MT, Kim JT, Ambrósio R, Belin MW, Grewal SPS, Yan W, et al. International values of central pachymetry in normal subjects by rotating scheimpflug camera. Asia Pac $J$ Ophthalmol (Phila) 2012; 1:13-8.

9. Khachikian SS, Belin MW. Posterior elevation in keratoconus. Ophthalmology 2009; 116:816

10. Guidance for industry. Collection of race and ethnicity data in clinical trials. U.S. Department of health and human services, food and drug administration, 2005. Available at: http:// www.fda.gov/downloads/Regulatory information/Guidances/ ucm 126396.pdf. Document issued on October 26, 2016

11. Cumming $A B$, Mascharka N. Outcomes after topography based LASIK and LASEK with the wavelight oculyzer and topolyzer platforms. J Refract Surgery 2010; 26:478-85. 
12. Ambrosio R Jr, Caiado AL, Guerra FP, Louzada R, Roy AS, Luz A, et al. Novel pachymetric parameters based on corneal tomography for diagnosing keratoconus. J Refract Surg 2011; 27:753-8.

13. Gilani F, Cortese M, Ambrósio RR, Lopes B, Ramos I, Harvey EM, et al. Comprehensive anterior segment normal values generated by rotating Scheimpflug tomography. J Cataract Refract Surg. 2013; 39:1707-12.

14. Murata C, Mallmann F, Yamazaki E, Campos M. [Anterior ocular segment study with the Scheimpflug rotational camera in refractive surgery candidates]. Arq Bras Oftalmol 2007; 70:619-24.

15. Hashemi M, Falavarjani KG, Aghai GH, Aghdam KA, Gordiz A. Anterior segment study with the Pentacam Scheimpflug camera in refractive surgery candidates. Middle East Afr $\mathrm{J}$ Ophthalmol 2013; 20:212-6.

16. Feng MT, Belin MW, Ambrósio R, Grewal SPS, Yan W, Shaheen MS, et al. International values of corneal elevation in normal subjects by rotating Scheimpflug camera. J Cataract Refract Surg 2011; 37:1817-21.

-........... 